Gut and Liver, Vol. 14, No. 6, November 2020, pp. 808-816

\title{
A Survey of the Knowledge of and Testing Rate for Hepatitis C in the General Population in South Korea
}

\author{
Gwang Hyeon Choi, Eun Sun Jang, Jin-Wook Kim, and Sook-Hyang Jeong \\ Department of Internal Medicine, Seoul National University Bundang Hospital, Seoul National University College of Medicine, Seongnam, Korea
}

Background/Aims: To eliminate hepatitis $\mathrm{C}$ virus (HCV) infection, improving public knowledge of and access to HCV screening and treatment is essential. The aim of this study was to evaluate the knowledge of and testing rate for HCV and the opinions about the inclusion of the HCV test in the National Health Examination (NHE) among the general population in South Korea. Methods: A telephone interview survey was conducted by an independent research company using a 16 item-questionnaire (demographics, knowledge of HCV, testing and results, need for screening) in May 2019. The sample population consisted of 1,003 adult Korean residents adjusted by age, sex, and area according to the standard Korean population in 2019. Results: Among the 1,003 participants (505 women, mean age of 47.9 years), $56.4 \%$ recognized $\mathrm{HCV}$; $44.4 \%$ understood that $\mathrm{HCV}$ is transmittable, and $56.8 \%$ thought that HCV is curable by medication. The recognition rate tended to increase with an increasing level of education. Testing for anti-HCV antibodies was reported by 91 people (9.1\%); among them, 10 people (11.0\%) reported a positive result, and eight people received treatment. The common reasons for HCV testing were a health check-up (58.5\%), a physician's recommendation (11.0\%) and elevated liver enzyme levels (10.7\%). The majority of the population (75.1\%) agreed with the integration of HCV into the NHE. Conclusions: The level of knowledge of HCV is suboptimal, and the self-reported testing rate for HCV is less than 10\%; however, once HCV infection is diagnosed, the treatment rate seems to be high in South Korea. More active campaigns and effective screening are needed. (Gut Liver 2020;14:808-816)

Key Words: Hepatitis C, chronic; Awareness; Knowledge; Transmission; Public health

\section{INTRODUCTION}

Hepatitis C virus (HCV) infection is a major public health concern because of its disease burden and communicability. Globally, approximately 71 million people have been infected with HCV, which could lead to liver cirrhosis and hepatocellular carcinoma. In 2015, HCV-related mortality was 400,000 per year showing an increasing number from 200,000 deaths in 2000 , which is in contrast to the decreasing trend of mortality from HIV (human immunodeficiency virus), tuberculosis and malaria. ${ }^{1,2}$

Patients with hepatitis C can be easily screened with an anti-HCV test, and more than 90\% of the patients are easily cured from a HCV infection with oral direct acting antiviral (DAA) therapy for 8 to 12 weeks, ${ }^{3,4}$ which stops the disease progression to liver cirrhosis and reduces the risk of hepatocellular carcinoma development. ${ }^{5-8}$ Considering that most of the mortality and medical cost was attributable to complications from liver cirrhosis and hepatocellular carcinoma, early diagnosis and treatment of HCV are a very important issue for promoting the public health. In this background, the World Health Organization has recently drafted a set of hepatitis elimination targets, which include a 65\% reduction in HCVrelated deaths and a 90\% reduction in HCV incidence by $2030 .^{2}$

In the era of DAA, under-diagnosis and gaps in linkage to care are the major barrier to the elimination of HCV. According to 2017 World Health Organization Global Hepatitis Report, only $20 \%$ of HCV, infected people are aware of their infection globally. ${ }^{9}$ However, the awareness rate was less than $10 \%$ in South-East Asia, ${ }^{10}$ where hepatitis B virus, not HCV, has been the major cause of liver-related mortality, and HCV was less recognized by the general population. Though public knowledge, awareness, attention and action are critically important

Correspondence to: Sook-Hyang Jeong

Department of Internal Medicine, Seoul National University Bundang Hospital, Seoul National University College of Medicine, 82 Gumi-ro 173beon-gil, Bundang-gu, Seongnam 13620, Korea

Tel: +82-31-787-7034, Fax: +82-31-787-4052, E-mail: jsh@snubh.org

Received on August 29, 2019. Revised on November 7, 2019. Accepted on November 25, 2019. Published online February $20,2020$.

pISSN 1976-2283 eISSN 2005-1212 https://doi.org/10.5009/gnl19296

@ This is an Open Access article distributed under the terms of the Creative Commons Attribution Non-Commercial License (http://creativecommons.org/licenses/by-nc/4.0) which permits unrestricted non-commercial use, distribution, and reproduction in any medium, provided the original work is properly cited. 
to make a successful elimination strategy, there are only a few studies on the public knowledge and screening rate of HCV in East Asian countries. In South Korea, where the anti-HCV prevalence is $0.7 \%$, no effective HCV screening program is operating yet. Therefore, the aims of this study were to evaluate the knowledge and self-reported testing rate of HCV and to assess public opinion about HCV screening among the general population of South Korea in 2019.

\section{MATERIALS AND METHODS}

\section{Sampling procedure and telephone survey}

The telephone interview survey was conducted by trained interviewers from a professional survey company (Gallup Korea, Seoul) in May 2019. A nationwide random sample of telephone numbers was obtained to conduct the survey. These telephone numbers were randomly selected from eight provinces of South Korea based on a per capita ratio using a random digit-dialing program which is the gold standard methodology for control recruitment in population-based epidemiologic research. ${ }^{11,12}$ The ratio of fixed-line and cordless calls was 20:80 and weighted by sex, age, and area based on the resident registration population from the Ministry of the Interior and Safety at the end of January 2019. ${ }^{13}$ A sex-, age-, and area-random sample of 1,003 respondents, aged more than 19 years, was obtained.

All telephone contacts were tracked and recorded on a database. Before the telephone interview, the interviewer explained to all eligible individuals the purpose of the study and requested their participation. Respondents gave informed verbal consent before the survey, and all respondents were interviewed by telephone survey interviewer. The response rate was $17 \%$, and this survey had a margin of error of $\pm 3.1 \%$ point at a $95 \%$ level of confidence.

This study was approved by the Institutional Review Board of Seoul National University Bundang Hospital (IRB number: X-1905/543-901).

\section{Questionnaire}

The questionnaire contained 16 questions including five demographic questions (age, sex, resident area, education level, and monthly income), five knowledge and five testing state questions and one public opinion question about HCV shown below. The Korean version of the questionnaire form used in this study is presented in Supplementary Fig. 1.

Part 1 Questions: Knowledge of hepatitis C in the general population; (1) Have you ever heard about HCV? (2) Do you think HCV is transmittable? (3) Can HCV be transmitted by tattooing, syringe use or acupuncture? (4) Should hepatitis C patients use separate dishes or towels from others? (5) Do you think HCV can be cured with drug therapy?

Part 2 Questions: Testing state of hepatitis $C$ in the general population; (1) Have you ever been tested for anti-HCV? (2)
Why did you get tested for anti-HCV? (3) What was the test result? (4) If you were diagnosed with hepatitis $\mathrm{C}$, did you get treatment? (5) If you were treated, what type of drugs were you prescribed (injection type drug or all oral drugs)?

Part 3 Question: Public opinion about HCV screening among the general population; Do you think anti-HCV testing should be included in the National Health Examination?

\section{Statistical analysis}

Tables were constructed for frequency and percentage. The baseline characteristics of the subjects were compared by the chi-square test for categorical variables, and the t-test was used to compare continuous variables. All p-values were two-sided, and $<0.05$ was considered significant. The SPSS version 21 (IBM Corp., Chicago, IL, USA) software was used for the statistical analyses.

Post-stratification weighting adjustment was applied to make the weighted records represent the population of inference as closely as possible. ${ }^{14}$ The post-stratification variables included sex (male/female), five age groups (19-29, 30-39, 40-49, 50-59, and $\geq 60$ years), and eight census regions (Seoul, Incheon/Gyeonggi, Gangwon, Daejeon/Sejong/Chungcheong, Daegu/Gyeongbuk, Busan/Ulsan/Gyeongnam, Gwangju/Jeolla, and Jeju). Because the study sample sizes were typically too small to accommodate a complete cross-tabulation of all the survey variables with the benchmark variables, an iterative proportional fitting was used for the post-stratification weighting adjustment. This procedure adjusted the sample data back to the selected benchmark proportions. Through an iterative convergence process, the weighted sample data were optimally fitted to the marginal distributions.

\section{RESULTS}

\section{Characteristics of the study population}

The study population consisted of a random sample of 1,003 South Korean residents aged more than 19 years, who were stratified by age, sex and geographic difference. The mean age of the patients was 47.9 years with a male proportion of $49.6 \%$, and 54\% had an education level of a college degree or higher. The general characteristics of the study population before and after the adjustment are shown in Table 1.

\section{Knowledge status on HCV among the general population}

Among the 1,003 respondents, 56.4\% heard of hepatitis C, which was classified as the HCV recognition group (Fig. 1). The recognition rate tended to increase from the 20s to the $50 \mathrm{~s}$ and then decrease. While the HCV recognition rate showed no significant difference according to sex or geographic region, it tended to increase according to the increasing level of education and average household income, though it was not statistically significant: $80.4 \%$ in the high education group over a master's 
Table 1. Baseline Characteristics of the Study Subjects

\begin{tabular}{|c|c|c|c|}
\hline Characteristic & Study subjects & Adjusted subjects* & Whole adult South Korean \\
\hline No. & 1,003 & 1,003 & $43,044,713$ \\
\hline Male sex & $497(49.7)$ & $497(49.6)$ & $21,334,875(49.6)$ \\
\hline Age, yr & $49.6 \pm 17.4$ & $47.9 \pm 17.0$ & \\
\hline $19-29$ & $174(17.4)$ & $174(17.4)$ & $7,438,522(17.3)$ \\
\hline $30-39$ & $168(16.8)$ & $168(16.8)$ & 7,247,690 (16.8) \\
\hline $40-49$ & $196(19.6)$ & $196(19.6)$ & $8,484,276(19.7)$ \\
\hline $50-59$ & $203(20.2)$ & $202(20.2)$ & $8,629,296(20.0)$ \\
\hline $60-69$ & $139(13.9)$ & 139 (13.9) & 5,978,518 (13.9) \\
\hline $70-79$ & $89(8.8)$ & $89(8.8)$ & $3,505,803(8.1)$ \\
\hline$\geq 80$ & $34(3.4)$ & $34(3.4)$ & $1,760,608(4.1)$ \\
\hline \multicolumn{4}{|l|}{ Residence area } \\
\hline Seoul & $200(19.9)$ & $194(19.4)$ & $8,335,109(19.4)$ \\
\hline Incheon/Gyeonggi & $303(30.2)$ & $306(30.5)$ & $13,111,906(30.5)$ \\
\hline Gangwon & $30(3.0)$ & $30(3.0)$ & $1,299,071(3.0)$ \\
\hline Daejeon/Chungcheong & $105(10.5)$ & $106(10.5)$ & $4,534,192(10.5)$ \\
\hline Daegu/Gyeongbuk & $100(10.0)$ & $100(10.0)$ & $4,302,165(10.0)$ \\
\hline Busan/Ulsan/Gyeongnam & $152(15.2)$ & $155(15.4)$ & $6,644,809(15.4)$ \\
\hline Gwangju/Jeolla & $100(10.0)$ & $100(9.9)$ & $4,278,825(9.9)$ \\
\hline Jeju & $13(1.3)$ & $13(1.3)$ & $538,636(1.3)$ \\
\hline \multicolumn{4}{|l|}{ Education level } \\
\hline$\leq$ Elementary school & $88(8.7)$ & $88(8.7)$ & - \\
\hline Middle school & $68(6.8)$ & $68(6.8)$ & - \\
\hline High school & $272(27.2)$ & $272(27.2)$ & - \\
\hline University & $495(49.4)$ & $495(49.4)$ & - \\
\hline Graduate school & $46(4.6)$ & $46(4.6)$ & - \\
\hline Refuse to respond & $34(3.4)$ & $34(3.4)$ & - \\
\hline \multicolumn{4}{|c|}{ Average monthly income, USD* } \\
\hline$<1,275$ & $147(14.7)$ & $147(14.7)$ & - \\
\hline $1,275-2,550$ & $162(16.1)$ & $162(16.1)$ & - \\
\hline $2,550-3,400$ & $147(14.7)$ & $147(14.7)$ & - \\
\hline $3,400-4,675$ & $154(15.4)$ & $154(15.4)$ & - \\
\hline $4,675-7,225$ & $119(11.8)$ & 119 (11.8) & - \\
\hline$\geq 7,225$ & $73(7.2)$ & 73 (7.2) & - \\
\hline Refuse to respond & $201(20.0)$ & $201(20.0)$ & - \\
\hline
\end{tabular}

Data are presented as number (\%) or mean \pm SD. Weighted by sex, age, and area based on the resident population registered with the Ministry of the Interior and Safety at the end of January $2019 .^{13}$

USD, United States dollar.

*Based on South Korea Won to the USD exchange rate on July 12, 2019.

degree and $77.3 \%$ in the high-income group over 4,675 to 7,225 USD (United States dollars) per month, However, the HCV recognition rate was low among the highest income class $(\geq 7,225$ USD/month).

Among the 1,003 respondents, 44.4\% thought HCV is transmittable. After a suggestion that HCV is a communicable disease, $69.8 \%$ agreed to a parenteral route of transmission such as contamination from tattooing, syringe use or an acupuncture procedure. However, 55.2\% thought that HCV patients should use separate dishes or towels from others, which suggested fecal to oral transmission or by casual contact. Moreover, 56.8\% answered that HCV can be cured by adequate medication (Fig. 2).

The HCV recognition group generally had better knowledge compared to the HCV non-recognition group (Supplementary Table 1). The acquisition of correct knowledge about HCV tended to be lower in the people in their 60s or older, low level 


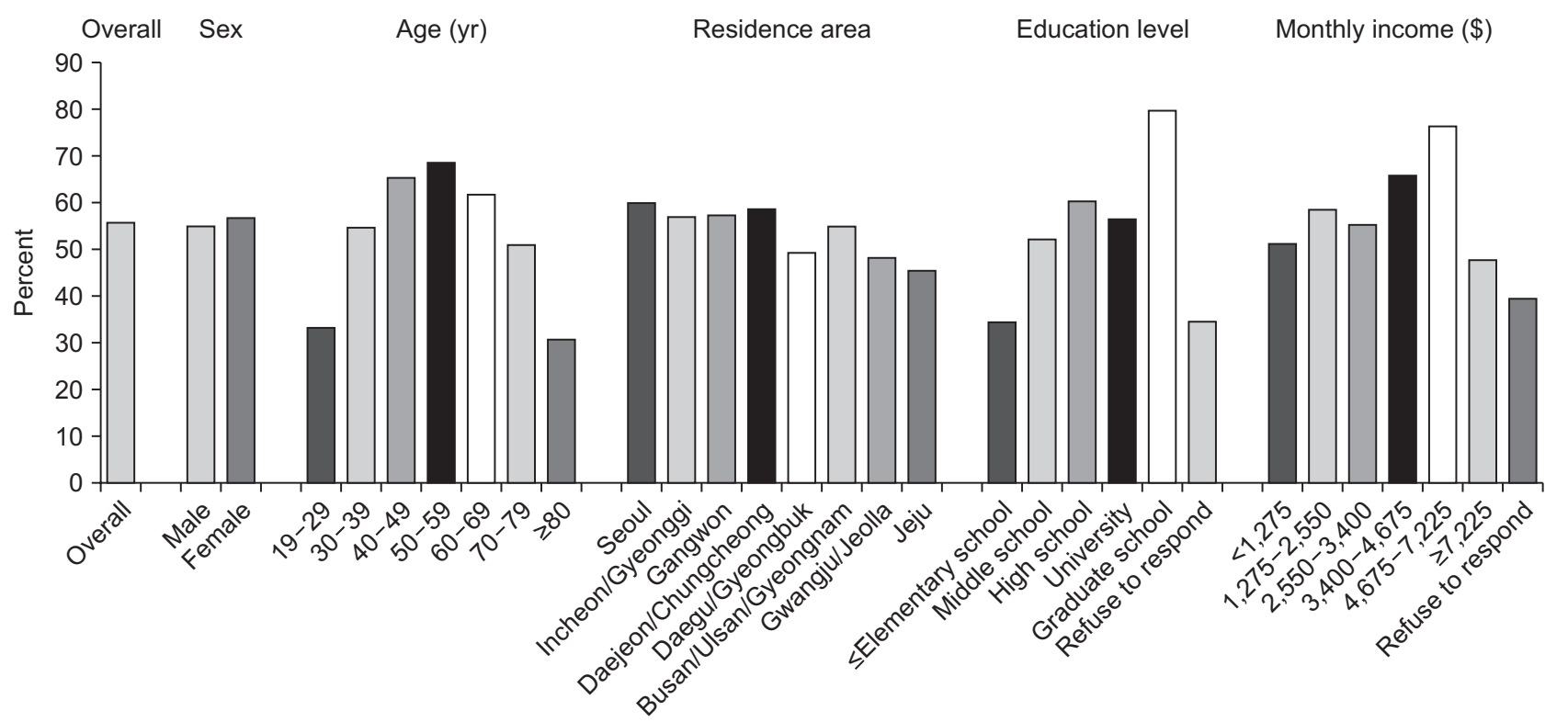

Fig. 1. Recognition rate of hepatitis C virus (HCV) among the general population of South Korea in 2019: positive response to the question "Have you ever heard about HCV?" Among the 1,003 survey respondents, 56.4\% had heard of hepatitis C. The recognition rate tended to increase from respondents in their 20s to those in their 50s and then decrease. While the HCV recognition rate showed no significant difference according to sex or geographic region, it tended to increase with increasing levels of education and average household income, though the associations were not statistically significant. Margin of error: $\pm 3.1 \%$ (95\% confidence interval).

\section{A. Do you think HCV is transmittable? \\ B. Should hepatitis $C$ patients use separate dishes or towels from others? \\ C. Can HCV be transmitted by tattooing, syringe use or acupuncture? \\ D. Do you think HCV can be cured with drug therapy?}

E. Do you think anti-HCV testing should be included in the National Health Examination?
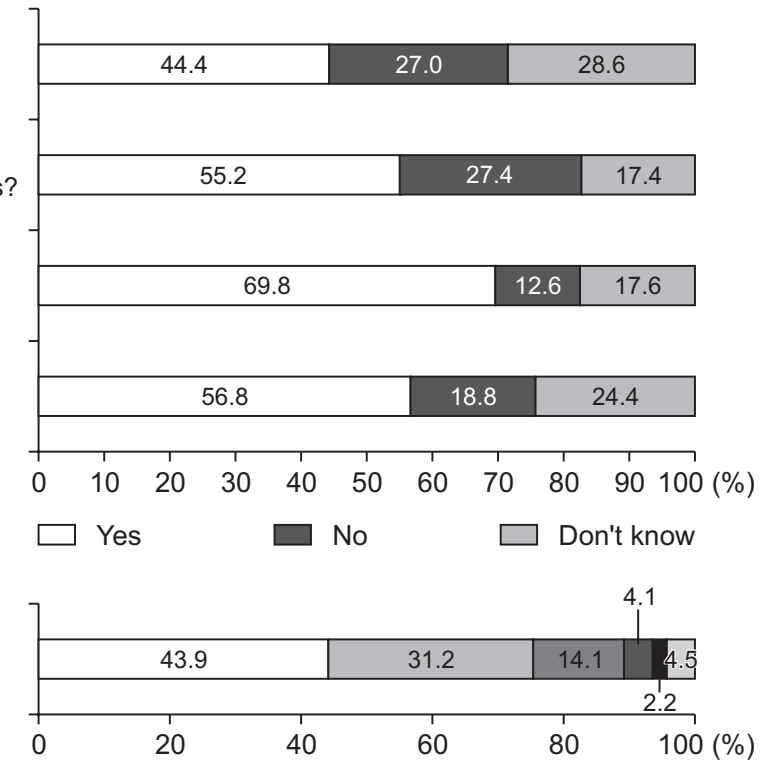

$\square$ Very necessary
$\square$ Somewhat necessary
$\square$ Neither necessary
nor unnecessary

Fig. 2. The knowledge of hepatitis $C$ virus (HCV) and opinions about the inclusion of the HCV test in the National Health Examination. Among the 1,003 respondents, $44.4 \%$ thought HCV is transmittable, $69.8 \%$ thought there was a parenteral route of transmission, and 56.8\% believed that HCV can be cured by adequate medication. The majority of respondents $(75.1 \%)$ agreed that an antiHCV test should be included as a basic item in the National Health Examination. Margin of error: $\pm 3.1 \%$ ( $95 \%$ confidence interval). of education (below middle school degree), and lowest monthly income ( $<1,275$ USD), and living in the Gwangju/Jeolla area (Table 2, Supplementary Tables 2-5). The Gwangju/Jeolla area had the second highest mean age and the second lowest college graduate rate and monthly income among the eight areas.

\section{Self-reported HCV testing rate and its result in the Korean general population}

Among the 1,003 subjects, 91 (9.1\%) reported that they had received an HCV test (Fig. 3A). The reasons why they had undergone HCV testing were health check-up (58.5\%), physician's recommendation (11.0\%), elevated liver enzymes (10.7\%), ac- 
Table 2. Self-Reported HCV Testing Rate in the General Korean Population Stratified by Subgroup

\begin{tabular}{|c|c|c|c|}
\hline Subgroup & No. & $\begin{array}{c}\text { Exam } \\
\text { rate, \% }\end{array}$ & p-value \\
\hline Overall & 1,003 & $91(9.1)$ & - \\
\hline Sex & & & 0.34 \\
\hline Male & 498 & $50(10.0)$ & \\
\hline Female & 506 & $42(8.3)$ & \\
\hline Age, yr & & & 0.02 \\
\hline $19-29$ & 174 & $4(2.3)$ & \\
\hline $30-39$ & 168 & 19 (11.3) & \\
\hline $40-49$ & 196 & $18(9.2)$ & \\
\hline $50-59$ & 203 & 23 (11.3) & \\
\hline $60-69$ & 140 & 18 (12.9) & \\
\hline $70-79$ & 89 & $8(9.0)$ & \\
\hline$\geq 80$ & 34 & $2(5.9)$ & \\
\hline Residence area & & & 0.76 \\
\hline Seoul & 196 & $19(9.7)$ & \\
\hline Incheon/Gyeonggi & 306 & $31(10.1)$ & \\
\hline Gangwon & 30 & $2(6.7)$ & \\
\hline Daejeon/Chungcheong & 106 & $11(10.4)$ & \\
\hline Daegu/Gyeongbuk & 101 & $7(6.9)$ & \\
\hline Busan/Ulsan/Gyeongnam & 155 & $16(10.3)$ & \\
\hline Gwangju/Jeolla & 100 & $6(6.0)$ & \\
\hline Jeju & 13 & 0 & \\
\hline Education level & & & 0.19 \\
\hline$\leq$ Elementary school & 87 & $5(5.7)$ & \\
\hline Middle school & 68 & $5(7.4)$ & \\
\hline High school & 272 & $25(9.2)$ & \\
\hline University & 495 & $45(9.1)$ & \\
\hline Graduate school & 46 & 9 (19.6) & \\
\hline Refuse to respond & 34 & $3(8.8)$ & \\
\hline Average monthly income, USD* & & & 0.16 \\
\hline$<1,275$ & 147 & $14(9.5)$ & \\
\hline $1,275-2,550$ & 161 & $12(7.5)$ & \\
\hline $2,550-3,400$ & 147 & $9(6.1)$ & \\
\hline $3,400-4,675$ & 155 & $17(11.0)$ & \\
\hline $4,675-7,225$ & 118 & $18(15.3)$ & \\
\hline$\geq 7,225$ & 73 & 7 (9.6) & \\
\hline Refuse to respond & 201 & $14(7.0)$ & \\
\hline
\end{tabular}

Weighted by sex, age, and area based on the resident population registered with the Ministry of the Interior and Safety at the end of January 2019. ${ }^{13}$

$\mathrm{HCV}$, hepatitis C virus; USD, United States dollar.

*Based on South Korea Won to the USD exchange rate on July 12, 2019.

quaintances' advice (9.3\%), family history of liver disease (8.0\%) and exposure in mass media (3.5\%) (Fig. 3B). The HCV testing rate was significantly low in the young age group with those in their 20s, but the people in their 30s and above had a similar testing rate from $9 \%$ to $12.9 \%$ according to increasing age (Table 2, Fig. 3).

\section{Treatment pattern among the respondents with a posi- tive anti-HCV test}

Among the 91 testing people, 10 (11.0\%) were reported that their anti-HCV testing result was positive: seven men and three women. Based on geographic distribution, there were two (1.0\%) in Seoul, two (0.7\%) in Incheon/Gyeonggi, four (3.8\%) in Daejeon/Chungcheong/Sejong, two (2.0\%) in Gwangju-Jeolla, one (0.6\%) in Busan/Ulsan/Gyeongnam, Gangwon and 0 in Daegu/ Gyeongbuk, and Jeju. The reasons for the anti-HCV testing were health check-up ( $n=4)$, elevated liver enzyme $(n=4)$, and physician's recommendation $(n=2)$. Among the 10 anti-HCV positive people, five were treated with an injection type drugs (probably pegylated interferon-based regimen) and three with all oral drugs. Interestingly, only four among the 10 respondents thought HCV is transmittable.

\section{Necessity of HCV antibody test for nationwide health check-up}

Though the information that the prevalence of hepatitis $\mathrm{C}$ in South Korea is less than 1\% was given to the participants, $75.1 \%$ (very necessary $43.9 \%$ and somewhat necessary $32.2 \%$ ) agreed that an anti-HCV test should be included as a basic item for the National Health Exam (Fig. 2). In particular, people in their 50 s to 70 s had a high agreement rate of over $80 \%$. All subgroups had a high favor rate of over $70 \%$ regardless of the geographic region and average household income (Supplementary Table 6).

\section{DISCUSSION}

In this telephone interview survey study, 56.4\% of the general population of South Korea recognized HCV, 44.4\% understood HCV is transmissible, and $56.4 \%$ thought HCV is curable by medication. Recognition of HCV was highest in the age group of 50 s and 60s, while knowledge on HCV was highest in the 20s. Testing an HCV test was reported in 91 people (9.1\%), in them, 10 people (11.0\%) reported as anti-HCV positive, and eight were treated. The major reason of HCV testing was health check-up (58.5\%), and majority (75.1\%) agreed to HCV screening by integration into National Health Examination system.

In South Korea, the anti-HCV prevalence adjusted for age, sex, and area among 291,314 health examinees ( $\geq 20$ years of age) was $0.78 \%$ in 2009 and $0.6 \%$ in $2015 .{ }^{15,16}$ The anti-HCV prevalence increased with age, and it was higher in females $(0.83 \%)$ than in males $(0.75 \%)$, showing intranational geographic difference: a higher prevalence (1.53\% to 2.07\%) in the southern coastal area. More than $90 \%$ of Korean patients with chronic HCV infection were over 40 years of age, and more than half of the patients were asymptomatic or showing alanine 
A

Testing rate of anti-HCV test

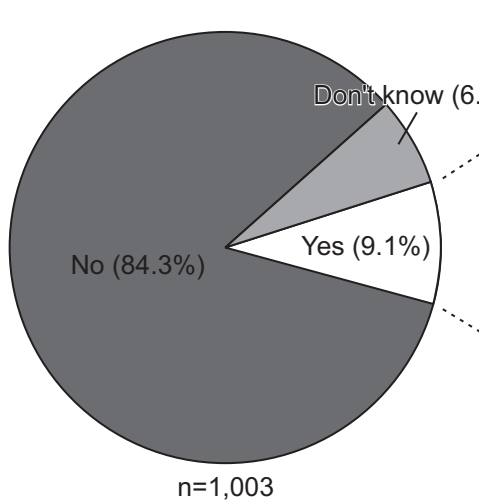

B

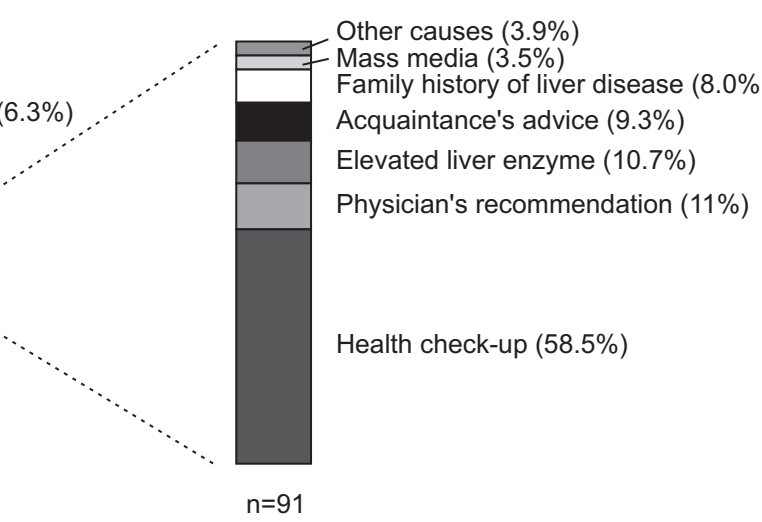

Fig. 3. Self-reported hepatitis C virus (HCV) testing rate and reasons for testing in the Korean general population in 2019. (A) Testing rate with the anti-HCV test. Testing for anti-HCV was reported by 91 people among the 1,003 survey subjects $(9.1 \%)$. (B) The reasons for receiving the anti-HCV test. The common reasons for HCV testing were a health check-up (58.5\%), a physician's recommendation (11.0\%) and elevated liver enzyme levels (10.7\%). Margin of error: $\pm 3.1 \%$ (95\% confidence interval). aminotransferase levels within normal limits at their diagnosis of chronic hepatitis C. The major HCV genotypes are 1b (48\%) and $2(46 \%) .{ }^{17}$ It was reported that a one-time HCV screening and DAA treatment of the Korean population aged 40 to 65 years would be highly cost-effective and significantly reduce the HCV-related morbidity and mortality (incremental cost-effectiveness ratio of 7,435 USD compared with no screening). ${ }^{18,19}$ However, the anti-HCV test is not integrated in the National Health Examination system yet, which is the most efficient way of achieving HCV screening in Korea.

It is interesting that HCV is still recognized only in half of the adult population because two episodes of a HCV outbreak in two local clinics were extensively reported in the media in $2015^{20}$ and 2017, respectively, and even one doctor at a clinic committed suicide during an investigation into the outbreak. The recognition rate tends to increase according to age, geographic region, and increasing level of education and income. The low prevalence of anti-HCV (0.34\%) in the young adult group (<30 years) and in the Jeju area (0.26\%) in 2009 may be an explanation, and generally, a high education level and income were related to a high awareness and knowledge of diseases including $\mathrm{HCV}^{21-23}$ In terms of treatment, 57\% of people thought HCV is curable with medication, which is far below the 95\% of the real life efficacy of DAA, recently.

For the knowledge about HCV, 56\% of the people did not know HCV is communicable, and 70\% of the people thought HCV patients should use separate dishes and towels, which suggests that the majority of the people consider HCV to be transmitted by casual contact or food. These prejudices may socially alienate HCV patients; therefore, widely spreading accurate knowledge is important not only for the prevention of HCV infection but also for the protection of HCV patients, socially.

This study is the first survey conducted in a representative population adjusted for the sex, age, and residence area of the population of South Korea, regarding the knowledge and HCV testing rate of HCV. Previously, there were three survey results on the knowledge of HCV in Korea: two online surveys in the general population and one face-to face survey for health check examinees, all of which did not include people aged over 70 years, with a much smaller number of questions than in this study, and were not published in academic journals but reported to public media (Table 3). In addition, the relative strength of the phone survey in this study compared to online surveys is the interactive communication between the interviewer and respondent. $^{24}$

Despite the methodological difference of the above three surveys compared to the one in this study, the self-reported testing rate of anti-HCV in this study ( $9 \%, n=91)$ was quite similar to the previous survey results (10\% to $12 \%)$, showing that the HCV screening rate has not improved during the recent 6 years (Table 3). However, South Korea has a welfare system called the National Health Examination, which is effective for early detection of diseases including five major cancers and metabolic diseases (diabetes and dyslipidemia). Though hepatitis $B$ virus surface antigen and antibody tests are included in the National Health Examination, which are fully paid by the national health insurance, the anti-HCV test is not included in the National Health Examination yet. In this study, 75\% of the population agree that the HCV screening test should be included in the National Health Examination system; moreover, $82 \%$ of health check examinees in the other survey also agreed to its inclusion in the National Health Examination, which was supported by several cost-effectiveness studies already published. ${ }^{18,25,26}$

In this study, the anti-HCV positive rate among the respondents was unexpectedly high $(11.0 \%, 10 / 91)$ considering that current anti-HCV prevalence among the Korean adult population of $0.6 \%$ to $0.8 \% .^{15,16}$ It may be related to the inherent limitation of telephone survey and its low response rate. In our study, the response rate of the telephone survey was 17\%, however, it was a relatively higher rate compared to those in the other surveys on many political or economic issues: general response rate in telephone survey is within the rage of $10 \%$ to $20 \%$ according to Gallop Korea. Moreover, anti-HCV test- 
Table 3. Comparison of the Survey Results Regarding HCV in South Korea

\begin{tabular}{|c|c|c|c|c|}
\hline \multirow{2}{*}{ Survey } & \multicolumn{4}{|c|}{ Year } \\
\hline & 2019 & 2017 & 2016 & 2013 \\
\hline Survey method & Telephone & Face-to-face & Online & Online \\
\hline Subjects & $\begin{array}{c}\text { General population } \\
\text { weighed by sex, } \\
\text { age, and region }\end{array}$ & Health examinee & $\begin{array}{c}\text { General population } \\
\text { weighed by sex, } \\
\text { age, and region }\end{array}$ & $\begin{array}{l}\text { General population } \\
\text { weighed by sex, } \\
\text { age, and region }\end{array}$ \\
\hline Age, yr & $19-90$ & $>20$ & $20-59$ & $14-69$ \\
\hline No. & 1,003 & 600 & 2,000 & 3,000 \\
\hline Have you ever heard about HCV? & 56.4 & - & 76 & - \\
\hline Do you think HCV is transmittable? & 44.4 & - & - & - \\
\hline $\begin{array}{l}\text { Should hepatitis C patients use separate dishes or } \\
\text { towels from others? }\end{array}$ & 55.2 & - & $16-38$ & 63.1 \\
\hline $\begin{array}{l}\text { Can HCV be transmitted by tattooing, syringe use } \\
\text { or acupuncture? }\end{array}$ & 69.8 & - & 66 & - \\
\hline Do you think HCV can be cured with drug therapy? & 56.8 & 44 & - & 82.3 \\
\hline $\begin{array}{l}\text { Do you think anti-HCV testing should be included } \\
\text { in the National Health Examination? }\end{array}$ & 75.1 & 82 & - & - \\
\hline Have you ever tested anti-HCV? & 9.1 & 10.4 & 12.2 & 10.4 \\
\hline Why did you test anti-HCV? & $\begin{array}{l}\text { Health check-up } \\
\text { (58.5) } \\
\text { Physicians' recom- } \\
\text { mend (11) } \\
\text { Elevated liver enzyme } \\
\text { (10.7) } \\
\text { Acquaintances' advise } \\
\text { (9.3) } \\
\text { Family history of } \\
\text { liver disease (8.0) }\end{array}$ & - & - & - \\
\hline $\begin{array}{l}\text { Self-reported positive rate of anti-HCV among } \\
\text { HCV testing people }\end{array}$ & 10.9 & - & 12.7 & 15.4 \\
\hline $\begin{array}{l}\text { Self-reported positive rate of anti-HCV among } \\
\text { the total subjects }\end{array}$ & 1.0 & - & 1.6 & 1.6 \\
\hline $\begin{array}{l}\text { Treatment rate among the self-reported anti-HCV } \\
\text { positive people }\end{array}$ & 80 & - & 65 & - \\
\hline
\end{tabular}

The answer to the question was expressed in percent.

$\mathrm{HCV}$, hepatitis $\mathrm{C}$ virus.

ing may be incorporated with other blood tests during routine health examination, in the workplace or a visit to clinic, which may not notify the participants. Therefore, anti-HCV testing rate may be underestimated, because it only depends on the respondent's report. In addition, recall bias may contribute either to underestimated anti-HCV testing rate or overestimation of the positive rate of anti-HCV. For example, 91 tested subjects may have more interest in or risk factors for HCV infection than the remaining non-tested group, which may result in a high antiHCV positive rate.
Interestingly, among the 10 anti-HCV positive people, eight were treated with probably pegylated interferon-based therapy or all oral DAA therapy. Therefore, once diagnosed, the treatment rate seems to be high in South Korea probably because of the high accessibility to health care and relatively low cost of DAA therapy under the coverage of the national health insurance (average out-of-pocket cost of DAA therapy per patient is approximately 2,700 USD, which is 30\% of the total cost of DAAs, and $70 \%$ of the cost is covered by the national health insurance). 
Awareness of HCV infection is one of the important factors to linkage of care. In recent studies, 55.6\% of the people in the United States, $36.2 \%$ to $66.5 \%$ in Taiwan, and $79.5 \%$ in Italy were aware of their HCV infection. ${ }^{21,27-29}$ There was only one published study in South Korea, which reported that 34.9\% of anti-HCV positive health check examinees were aware of their infection status between 2001 and $2008 .^{30}$ In previous studies, awareness is usually defined as one's own recognition of HCV infection status, which was verified by anti-HCV results. However, this study did not perform the anti-HCV test for the subjects; therefore, we did not evaluate the verified awareness rate of HCV in South Korea.

This study has several limitations. First, willingness to participate in research could be an inevitable bias in this kind of survey. However, the authors corrected the data through high quality national demographic data and cited the adjusted proportion as the main result of the study. Second, as the anti$\mathrm{HCV}$ testing rate and anti-HCV positive rate are calculated by the respondent's statement, recall bias and possible selection bias may affect the results. Third, only 10 patients were reported as HCV positive; thus, it was difficult to generalize the distribution of age, sex, and area and behavior pattern such as treatment rate and regimen. Finally, knowledge and testing rate of HCV can be influenced by the level of education; this survey did not adjust for the level of education to the national population statistics.

In conclusion, the level of knowledge and testing rate of HCV were relatively low despite the high education level of South Korea. In addition, the majority of the respondents favored the introduction of universal anti-HCV testing through the National Health Examination, especially when people are asymptomatic. To eliminate HCV, publicity and education about HCV are needed, and it is necessary to consider introducing the HCV test to asymptomatic health examinees.

\section{CONFLICTS OF INTEREST}

No potential conflict of interest relevant to this article was reported.

\section{ACKNOWLEDGEMENTS}

This study was supported by a grant of the Chronic Infectious Disease Cohort Study (Korea HCV Cohort Study, 4800-4859304) from the Korea Centers for Disease Control and Prevention.

We thank Sung Soo Lim, Ki Won Yoon of Gallup Korea for their help with reliable survey.

\section{AUTHOR CONTRIBUTIONS}

Study concept and design, data acquisition, analysis, and interpretation, statistical analysis, and manuscript drafting: G.H.C.,
S.H.J. Data acquisition, analysis, and interpretation support: E.S.J., J.W.K. Approval of final manuscript: all authors.

\section{ORCID}

Gwang Hyeon Choi https://orcid.org/0000-0002-8795-8427

Eun Sun Jang https://orcid.org/0000-0003-4274-2582

Jin-Wook Kim https://orcid.org/0000-0003-0934-3344

Sook-Hyang Jeong https://orcid.org/0000-0002-4916-7990

\section{REFERENCES}

1. Lombardi A, Mondelli MU; ESCMID Study Group for Viral Hepatitis (ESGVH). Hepatitis C: is eradication possible? Liver Int 2019;39:416-426.

2. World Health Organization (WHO). Combating hepatitis B and C to reach elimination by 2030: advocacy brief [Internet]. Geneva: WHO; c2016 [cited 2019 Dec 16]. Available from: https://www. who.int/hepatitis/publications/hep-elimination-by-2030-brief/en/.

3. Falade-Nwulia O, Suarez-Cuervo C, Nelson DR, Fried MW, Segal JB, Sulkowski MS. Oral direct-acting agent therapy for hepatitis C virus infection: a systematic review. Ann Intern Med 2017;166:637-648.

4. Majumdar A, Kitson MT, Roberts SK. Systematic review: current concepts and challenges for the direct-acting antiviral era in hepatitis C cirrhosis. Aliment Pharmacol Ther 2016;43:1276-1292.

5. Carrat F, Fontaine H, Dorival C, et al. Clinical outcomes in patients with chronic hepatitis $\mathrm{C}$ after direct-acting antiviral treatment: a prospective cohort study. Lancet 2019;393:1453-1464.

6. Nahon P, Bourcier V, Layese R, et al. Eradication of hepatitis C virus infection in patients with cirrhosis reduces risk of liver and non-liver complications. Gastroenterology 2017;152:142-156.

7. Calvaruso V, Cabibbo G, Cacciola I, et al. Incidence of hepatocellular carcinoma in patients with HCV-associated cirrhosis treated with direct-acting antiviral agents. Gastroenterology 2018;155:411-421.

8. Ioannou GN, Green PK, Berry K. HCV eradication induced by direct-acting antiviral agents reduces the risk of hepatocellular carcinoma. J Hepatol 2018;68:25-32.

9. World Health Organization (WHO). Global hepatitis report, 2017 [Internet]. Geneva: WHO; c2017 [cited 2019 Dec 16]. Available from: https://www.who.int/hepatitis/publications/global-hepatitisreport2017/en/.

10. World Hepatitis Alliance. World Hepatitis Day 2018: Global Summary Report [Internet]. London: World Hepatitis Alliance; c2019 [cited 2020 Jan 16]. Available from: https://www.worldhepatitisday.org/.

11. Clagett B, Nathanson KL, Ciosek SL, et al. Comparison of addressbased sampling and random-digit dialing methods for recruiting young men as controls in a case-control study of testicular cancer susceptibility. Am J Epidemiol 2013;178:1638-1647.

12. Gundersen DA, ZuWallack RS, Dayton J, Echeverría SE, Delnevo 
CD. Assessing the feasibility and sample quality of a national random-digit dialing cellular phone survey of young adults. Am J Epidemiol 2014;179:39-47.

13. Ministry of the Interior and Safety. Resident population and household status [Internet]. Sejong: Ministry of the Interior and Safety [cited 2019 Dec 15]. Available from: https://www.mois. go.kr/eng/a01/engMain.do.

14. Kalton G, Flores-Cervantes I. Weighting methods. J Off Stat 2003;19:81-97.

15. Kim DY, Kim IH, Jeong SH, et al. A nationwide seroepidemiology of hepatitis C virus infection in South Korea. Liver Int 2013;33:586-594.

16. Jang ES, Ki M, Choi HY, Kim KA, Jeong SH; Korean Hepatitis Epidemiology Study Group. The change in the nationwide seroprevalence of hepatitis C virus and the status of linkage to care in South Korea from 2009 to 2015. Hepatol Int 2019;13:599-608.

17. Nam JY, Jang ES, Kim YS, et al. Epidemiological and clinical characteristics of hepatitis C virus infection in South Korea from 2007 to 2017: a prospective multicenter cohort study. Gut Liver 2020;14:207-217.

18. Kim KA, Chung W, Choi HY, Ki M, Jang ES, Jeong SH. Cost-effectiveness and health-related outcomes of screening for hepatitis $C$ in Korean population. Liver Int 2019;39:60-69.

19. Korean Association for the Study of the Liver. KASL clinical practice guidelines: management of hepatitis C. Clin Mol Hepatol 2016;22:76-139.

20. Chung YS, Choi JY, Han MG, et al. A large healthcare-associated outbreak of hepatitis C virus genotype 1a in a clinic in Korea. J Clin Virol 2018;106:53-57.

21. Kim HS, Yang JD, El-Serag HB, Kanwal F. Awareness of chronic viral hepatitis in the United States: an update from the National Health and Nutrition Examination Survey. J Viral Hepat 2019;26:596-602.
22. Rajamoorthy Y, Taib NM, Munusamy S, et al. Knowledge and awareness of hepatitis B among households in Malaysia: a community-based cross-sectional survey. BMC Public Health 2019;19:47.

23. Hang Pham TT, Le TX, Nguyen DT, et al. Knowledge, attitudes and practices of hepatitis B prevention and immunization of pregnant women and mothers in northern Vietnam. PLoS One 2019;14:e0208154.

24. Wright KB. Researching internet-based populations: advantages and disadvantages of online survey research, online questionnaire authoring software packages, and web survey services. J Comput Media Commun 2017;10:JCMC1034.

25. Coffin PO, Scott JD, Golden MR, Sullivan SD. Cost-effectiveness and population outcomes of general population screening for hepatitis C. Clin Infect Dis 2012;54:1259-1271.

26. Deuffic-Burban S, Huneau A, Verleene A, et al. Assessing the costeffectiveness of hepatitis C screening strategies in France. J Hepatol 2018;69:785-792.

27. Lin C, Clark R, Tu P, Tu R, Hsu YJ, Nien HC. The disconnect in hepatitis screening: participation rates, awareness of infection status, and treatment-seeking behavior. J Glob Health 2019;9:010426.

28. Andriulli A, Stroffolini T, Mariano A, et al. Declining prevalence and increasing awareness of HCV infection in Italy: a population-based survey in five metropolitan areas. Eur J Intern Med 2018;53:79-84.

29. Yu ML, Yeh ML, Tsai PC, et al. Huge gap between clinical efficacy and community effectiveness in the treatment of chronic hepatitis C: a nationwide survey in Taiwan. Medicine (Baltimore) 2015;94:e690.

30. Shin A, Cho ER, Kim J, et al. Factors associated with awareness of infection status among chronic hepatitis B and C carriers in Korea. Cancer Epidemiol Biomarkers Prev 2009;18:1894-1898. 